\title{
LA CONFIGURACIÓN DEL EFECTO DE LITERALIDAD EN LAS COLECCIONES ESCOLARES DE LITERATURA. EL CASO ARGENTINO
}

\author{
CAROLINA TOSI ${ }^{1}$ \\ Consejo Nacional de Investigaciones Científicas y Técnicas e \\ Instituto de Lingüística de la Facultad de Filosofía y Letras de la \\ Universidad de Buenos Aires, Argentina \\ carolinaltosi@gmail.com
}

\begin{abstract}
Resumen. Desde la perspectiva de la Teoría Polifónica de la Enunciación (DUCROT, 1984), en un corpus de treinta libros de literatura correspondientes a colecciones escolares editadas en la Argentina, analizamos ciertos mecanismos microdiscursivos presentes en las notas al pie, que contribuyen a producir el efecto de "literalidad". Tal efecto se sustenta en el imaginario - de extensa tradición en el ámbito escolar-de que existe un sentido literal en el texto y de que puede ser detectado en la materialidad discursiva. Por un lado, damos cuenta de que la función principal de las notas consiste en aportar definiciones e interpretaciones solapadas acerca del texto. Por el otro, analizamos la construcción del locutor y los destinatarios y, finalmente, indagamos el ideal de lectura configurado.
\end{abstract}

Palabras claves: literatura; colección escolar; polifonía; enunciación; literalidad.

Resumo. A partir da Teoria Polifônica da Enunciação (DUCROT, 1984), em um corpus de trinta livros de coleções escolares de literatura, publicadas na Argentina, analisamos certos mecanismos microdiscursivos presentes nas notas de rodapé, que contribuem para a produção de um efeito de "literalidade". Este efeito se sustenta no imaginário - de grande tradição no âmbito escolar - de que há um sentido literal no texto e que este pode ser detectado na materialidade discursiva. Por um lado, percebemos que a principal função das notas é proporcionar definições e interpretações que estão ocultas/sobrepostas no texto. Por outro lado, analisamos a construção do locutor e dos destinatários e, finalmente, questionamos o ideal de leitura configurado.

Palavras-chave: literatura; coleção escolar; polifonia; enunciação; literalidade.

\footnotetext{
${ }^{1}$ Doutora em Linguística pela Universidade de Buenos Aires, onde atua como docente e pesquisadora. http://il.institutos.filo.uba.ar/integrante/tosi-carolina-luciana.
} 


\begin{abstract}
In the framework of the Polyphonic Theory of Enunciation (DUCROT, 1984), in a corpus of thirty school books published in Argentina, we analyze certain microdiscursive mechanisms present in the footnotes, which contribute to produce an effect of "Literality". This effect is based on the imaginary - of long tradition in the school institution-that there is a literal meaning in the text and that it can be detected in the discursive materiality. On the one hand, we realize that the main function of the notes is to provide overlapping definitions and interpretations about the text. On the other hand, we analyze the construction of the speaker and the recipients and, finally, we investigate the configured reading ideal.
\end{abstract}

Keywords: literature; school collection; polyphony; enunciation; literality.

\title{
Introducción
}

Destinadas al público infantil y juvenil y concebidas para su lectura en la escuela, las colecciones escolares de literatura cuentan con una gran presencia en el mercado editorial argentino y poseen amplia circulación en las instituciones escolares. La mayoría de las colecciones se caracteriza por catálogos muñidos de textos clásicos y canónicos -muchos de ellos sugeridos por los diseños curriculares - y por presentar un paratexto editorial ${ }^{2}$ conformado por prólogos, notas al pie, anexos explicativos y actividades, que transforman y condicionan la recepción de las obras y habilitan diversos efectos de sentido. Efectivamente, todos estos elementos paratextuales prescriben determinados gestos de lectura y formas de abordar los textos. Teniendo en cuenta la relevancia de dicho tipo de ediciones en el ámbito educativo argentino, el objetivo de este trabajo consiste en aportar evidencias lingüístico-discursivas del modo en que estas vehiculizan representaciones sociales sobre la literatura, la lectura y los destinatarios.

En el marco de la Teoría Polifónica de la Enunciación (ANSCOMBRE Y DUCROT [1983] 1994 y DUCROT, 1984) y sobre la base de trabajos previos (TOSI, 2014, 2015 y 2016), en el presente artículo analizamos las notas al pie de página de un corpus de colecciones escolares de literatura editadas en la Argentina, que son leídas actualmente con asiduidad en los colegios primarios y secundarios.

Si bien existen algunas investigaciones que se han ocupado de caracterizar las colecciones escolares de literatura en la Argentina desde el enfoque de la Didáctica de la Literatura (BOMBINI, 2001 y 2004 y PIACENZA, 2001 y 2015), en esta ocasión y a partir de los estudios enunciativo-discursivos realizados por Orlandi (1990) y ZoppiFontana $(2007)^{3}$, nos proponemos a analizar ciertos mecanismos microdiscursivos

\footnotetext{
${ }^{2}$ El paratexto editorial, a cargo del editor, se ocupa de la transformación del texto en mercancía, y los diversos elementos que lo integran son marcas de ese proceso (ALVARADO, 1992). De acuerdo con Alvarado, el paratexto a cargo del editor lo constituyen desde tapas, contratapas y solapas hasta aspectos más vinculados con la realización material del libro, como la diagramación, la tipografía y la elección del papel. En nuestro caso de análisis, el editor organiza el paratexto editorial y un especialista en Literatura se encarga de la redacción de cada una de las secciones.

${ }^{3}$ Desde un enfoque enunciativo-discursivo, Orlandi analiza los prefacios y las notas al pie de las reediciones de los relatos de viaje escritos por misioneros y viajantes de procedencia francesa, en Brasil, durante los
} 
presentes en las notas al pie de página, que contribuyen a producir un efecto de "literalidad". Tal efecto se sustenta en el imaginario - de extensa tradición y enraizado en la escuela- de que existe un sentido literal en el texto y que, debido a que las palabras se corresponderían unívocamente con la "realidad", puede ser rastreado y detectado en la misma materialidad discursiva.

En lo que sigue, primero, exponemos brevemente el marco teórico que sustenta nuestro trabajo y, luego, caracterizamos ciertos aspectos metodológicos $(\$ 2)$. En segunda instancia, describimos la función de las notas al pie en los libros de literatura y brindamos precisiones teóricas acerca de las definiciones allí configuradas (\$3), para luego presentar el análisis propiamente dicho $(\S 4)$. Finalmente, puntualizamos las conclusiones a las que hemos arribado $(\S 5)$.

\section{Marco teórico y comentarios metodológicos}

\subsection{La Teoría Polifónica de la Enunciación}

Con relación a nuestro marco teórico, vale destacar que, según la Teoría Polifónica de la Enunciación (ANSCOMBRE y DUCROT, 1983 y DUCROT, 1984), la lengua no brinda información sobre el mundo, es decir, no refiere directamente al sentido en términos unívocos y transparentes. Por el contrario, la lengua se concibe a partir de indicaciones de carácter argumentativo y, por ello, la significación es de tipo instruccional y polifónico. En consecuencia, el sentido de los enunciados remite a otros discursos, que son o pueden ser su continuación.

Vale precisar que, para caracterizar la figura de locutor en nuestro corpus, seguimos los conceptos de Ducrot (1984), quien separa el sujeto empírico (SE), en tanto autor efectivo y productor del enunciado, de una serie de voces que aparecen en los distintos niveles del enunciado. Entre esta pluralidad de voces, que son instancias puramente discursivas, distingue al locutor como tal (L), que aparece como responsable de la enunciación (no necesariamente identificable con SE), del locutor como ser en el mundo (locutor $\lambda$ ), sujeto del enunciado y objeto de la enunciación (aquel que dice "yo"), y de los enunciadores, entendidos estos como puntos de vista presentes en el enunciado. Aquí nos centraremos en caracterizar a L y, de ahora en más, nos referiremos al locutorexperto como aquel que se configura en las notas al pie de página, brindando precisiones sobre el texto en su rol de especialista en Literatura, y lo distinguimos del locutor-escritor del texto literario en sí, de cuya construcción no nos ocuparemos, pues excede los objetivos planteados.

Específicamente, en este trabajo situado en el EDAPE (Enfoque Dialógico de

siglos XVI y XVII. Por su parte, Zoppi-Fontana aborda la edición de Marcovaldo overo, la stagioni in citta, de Italo Calvino, en su versión original en italiano publicado por Giulio Einaudi, en 1986. Dicha edición forma parte de una colección de textos destinados a la escuela media y cuyo aparato paratextual está a cargo del mismo autor. 
la Argumentación y de la Polifonía Enunciativas) ${ }^{4}$, analizamos ciertos aspectos relacionados con la construcción del sentido y los diferentes tipos de formulaciones encontradas en las notas al pie de nuestro corpus que, si bien tienden a producir un efecto de objetividad y neutralidad, pueden concebirse, sin embargo, como manifestaciones de la subjetividad y la alteridad, según demostraremos a lo largo del análisis.

\subsection{Algunos aspectos metodológicos y precisiones sobre el corpus}

Las primeras colecciones literarias destinadas a niños y jóvenes, editadas en la Argentina, se organizaron con los objetivos de acercar las obras clásicas a un público lego y de que circularan dentro del ámbito escolar. Guiado por dichos fines, ya desde mediados del siglo XX, este tipo de colecciones dispuso de espacios paratextuales que buscaban auxiliar al destinatario-alumno y destinatario-docente en el proceso de interpretación. Prólogos, anexos explicativos, notas al pie y actividades se desplegaron con la pretensión de indicar un modo de lectura y una forma de abordar los textos en el aula.

Bombini (2001) llama a dicho paratexto escolar - una innovación que el autor le adjudica a la colección GOLU- "notas del profesor", en la medida en que funcionan como espacios destinados al docente, ya que buscan auxiliarlo en la organización y el dictado de las clases.

Si bien no hay dudas de que el destinatario privilegiado de estas colecciones es el docente, como sostiene Bombini, no podemos soslayar la figura del otro destinatario construido: el alumno. En efecto, las notas al pie, objeto de análisis del presente trabajo, modelan no solo un docente que debe controlar los sentidos de la obra y por ello se le ofrece información extra para abordarla sin fisuras, sino también un alumno lego que desconoce cierta información -predominantemente, cultural y enciclopédica- al que hay que guiar en la comprensión y ofrecerle una lectura "andamiada", basada en el supuesto de que no podría hacerlo por sí solo.

Si nos referimos al mercado de las colecciones escolares de literatura editadas en la Argentina, encontramos una gran variedad y cantidad de sellos. Teniendo en cuenta la tradición, circulación y la renovación del catálogo, entre los principales sellos podemos mencionar a: GOLU, de Editorial Kapelusz, la pionera; Leer y Crear, de Editorial Colihue; Biblioteca Clásica y Contemporánea, de Editorial Losada; Colección del Mirador y Colección Azulejos del Grupo MacMillan; Colección de los Anotadores, de Editorial Mandioca; Serie Roja de Alfaguara; Grandes Lecturas de Editorial Salim y Edelvives Clásicos.

En cuanto al diseño de nuestra investigación, este se basó en la metodología cualitativa, puesto que los abordajes cualitativos se adecuan mejor al análisis de los discursos y los documentos; en efecto, dicho método permite develar procesos sociales referentes a objetos de estudio particulares y puede ser la base para la construcción de

\footnotetext{
${ }^{4}$ Se trata del grupo de investigación dirigido por la Dra. García Negroni en el Instituto de Lingüística (FFyL-UBA, Buenos Aires).
} 
nuevos conceptos y categorías de análisis (DE SOUZA MINAYO, 2009, p. 47). Como material de estudio, se conformó un corpus discursivo, compuesto por 30 libros pertenecientes a tres colecciones escolares de literatura, que fueron elegidas debido al criterio de relevancia editorial -es decir, presencia en el mercado y amplia circulación en los colegios-, a saber:

- Colección Leer y Crear (L y C). Editorial Colihue.

- Colección del Mirador. Editorial Cántaro. Grupo MacMillan.

- Colección de los Anotadores. La Estación. Editorial Mandioca.

Respecto de la primera colección, esta tiene una larga tradición y un catálogo muy nutrido. Muchas de sus obras, editadas entre las décadas de los 70 y 80 , cuentan con numerosas reimpresiones. Por ejemplo, Antígona Vélez de Leopoldo Marechal y El perjurio de la nieve de Adolfo Bioy Casares, editadas en 1982 y 1983, respectivamente, por L y C de Colihue, fueron reimpresas en forma continua hasta hoy en día. Las obras de las otras dos colecciones - de editoriales MacMillan y Mandioca- son de edición reciente -las que integran nuestro corpus fueron editadas entre 2007 y 2015.

Vale aclarar que se abordaron 10 libros de cada colección. Las obras que conforman el corpus pueden clasificarse en relatos clásicos, ya sea de literatura universal más antigua (como La Odisea o El lazarillo de Tormes) como más actual (El extraño caso del doctor Jekyll y el señor Hyde, de Robert Louis Stevenson o Moby Dick, de Herman Melville); latinoamericana (Cuentos de la selva, La gallina degollada y, en general, toda la producción de Horacio Quiroga); argentina (Martín Fierro de José Hernández o El matadero de Esteban Echeverría); antologías literarias (Cuatro cuentos policiales, de Poe, Doyle, Battista, Sorrentino y Mitelman de Colección del Mirador, o Cuentos españoles contemporáneos de L y C) y libros de autores argentinos contemporáneos (La fiesta ajena de Liliana Heker o El pan de la lectura de Carlos Gorostiza). Se trata de obras que, en general, forman parte del canon escolar -incluso, muchas de ellas son sugeridas por los diseños curriculares- y por ello son de lectura recurrente y obligatoria en las escuelas.

Cabe precisar que las colecciones abordadas presentan un aparato paratextual que acompaña la obra y que incluye un prólogo o introducción y notas al pie. Además, L y $\mathrm{C}$ y Mandioca ofrecen actividades o propuestas de trabajo para hacer en el aula.

Como ya adelantamos, en esta ocasión, nos dedicamos a analizar las notas al pie de página o notas laterales -esto dependerá de la maqueta de cada colección- ${ }^{5}$ que, en todos los casos abordados, están a cargo de un especialista en Literatura -suele tratarse de un profesor de escuela secundaria o universitaria.

En las tres colecciones el nombre del encargado de realizar el prólogo y las notas al pie figura en la página de créditos y legales, en la misma jerarquía que otros

\footnotetext{
${ }^{5}$ En la Colección de los Anotadores las notas son laterales, es decir se ubican en la columna de aire, al costado del texto literario central. En el resto de las colecciones, se trata de notas al pie. Debido a que cumplen la misma función, por una cuestión de unificación del término, nos referiremos siempre al nombre canónico: notas al pie.
} 
profesionales de la edición, como el editor, el corrector, el diseñador, etc. No se incluyen datos biográficos ni méritos profesionales del especialista. De esta forma, se observa la escasa relevancia dada al "comentador" del texto que suele pasar inadvertido para los lectores, que, por lo general, ni siquiera reparan en su nombre a la hora de seleccionar, o bien, de leer el libro.

\section{Las notas al pie en la literatura}

\subsection{La lectura literaria}

Como es sabido, la literatura puede definirse como plurisignificativa, pues no está cerrada a una única lectura, sino que se abre a múltiples significados y sentidos. Actualmente, desde los diseños curriculares de la Argentina y la didáctica de la literatura, se propone que la lectura literaria se vincule con el disfrute y la gratificación alcanzada por el lector y ya no con la mera aplicación de categorías de análisis relativas al trabajo escolar (COLOMER, 2010). De este modo, quien enseña literatura debería "provocar y expandir la respuesta provocada por el texto literario" y no "enseñar a ocultar la reacción personal a través del rápido refugio en categorías objetivas de análisis" (COLOMER, 2010, p. 9).

No obstante, ello, según afirma Colomer (2010), el tipo de lectura literaria que, por décadas se ha realizado en la escuela y que aún perdura en muchos espacios educativos, se ha limitado a que los alumnos asuman la interpretación del docente y se mantengan alejados de toda fruición personal de los textos. De esta forma, se tiende a forjar la imagen de que existe una lectura "correcta" que se enseña y se evalúa.

Si nos referimos las notas al pie en las colecciones de literatura, estas podrían concebirse como elementos paratextuales que tienden a estabilizar los sentidos y homogeneizar las interpretaciones. Por ejemplo, Orlandi (1990) caracteriza las notas como un movimiento descentralizador, ya que ellas estarían "diciendo con otras palabras" lo que estaba formulado en el texto principal. Por ende, "el funcionamiento de las notas puede concebirse como síntoma de que el texto es incompleto: la imposición de determinada lectura indica que otra lectura podría ocurrir" (ORLANDI, 1990, p. 116). Incluso, algunos teóricos las definen como "injertos normalizadores", en la medida en que "imponen sobre los desvíos y derivas abiertos por el texto narrativo una lectura literal" (ZOPPI-FONTANA, 2007, p. 29). Desde esta perspectiva, las notas al pie en el discurso literario operan como un dispositivo de control y legitimación de determinados gestos de interpretación, puesto que fijan sentidos y excluyen otros que, discursivamente, no son hegemónicos ${ }^{6}$.

\footnotetext{
${ }^{6} \mathrm{~A}$ su vez, Zoppi-Fontana indica que las notas funcionan como comentarios, en el sentido de Foucault (1970). El comentario es una forma de control discursivo, puesto que en toda sociedad "la producción del discurso está a la vez controlada, seleccionada y redistribuida por procedimientos que tienen por función conjurar poderes y peligros, dominar el acontecimiento aleatorio y esquivar su temible materialidad" (1970, p. 11).
} 
En lo que refiere a nuestro corpus, casi en su totalidad, las notas al pie aportan definiciones, pero también interpretaciones sobre los sentidos del texto. Configuradas como espacios pedagógicos, las notas no solo ofrecen información enciclopédica que pretendería ampliar el vocabulario de los alumnos, sino que, además y como demostraremos en el análisis, modelan una determinada interpretación.

\subsection{Las definiciones}

Lejos de entender la "definición" como una descripción, la corriente francesa del Análisis del Discurso la concibe como una forma de organización y de pretensión de una ilusoria "estabilidad". De esta perspectiva, Pêcheux (1975) postula que la definición permite dotar al mundo de estructura y escapar de la idea de la heterogeneidad e inseguridad. Por su parte, Orlandi (2009) plantea que el discurso pedagógico crea conclusiones exclusivas y tiende a la producción del sentido en una única dirección; la definición, entonces, al presentar la coincidencia entre las entidades y las frases que la definen, es una estrategia puesta al servicio de la generación del efecto de lectura unívoca y unidireccional.

Luego de haber rastreado e indagado las características y funciones de las definiciones en las notas al pie en nuestro corpus, las agrupamos en tres tipos que serán presentados a continuación en orden decreciente de despersonalización y de solapamiento en cuanto a la interpretación del texto que introducen. A través del análisis, se demostrará cómo los recursos de despersonalización desplegados para la formulación de las definiciones ocultan el punto de vista y el movimiento de reinterpretación del texto.

\section{EI análisis. Las definiciones en las notas de las colecciones literarias}

\section{a) Las definiciones por equivalencia: verbo ser y yuxtaposición}

Las definiciones del tipo "A es X" plantean una relación de equivalencia entre los componentes, dada a través del verbo "ser". Los glosarios así formulados parecen mostrar una correspondencia directa y unívoca entre cada uno de los términos definidos (generalmente, destacados en la nota en color o bastardilla) ${ }^{7}$ y la expresión que los explica. Como sostiene Ramírez Gelbes (2004), al tratarse de un verbo semánticamente vacío, "ser" suele funcionar como el signo "igual" en matemática, parangonando los dos miembros de la ecuación, o como si propusiera una verdad autónoma y absoluta, independiente de la instancia de la enunciación ${ }^{8}$. De esta manera y como lo confirman

\footnotetext{
${ }^{7}$ El destacado en color o bastadilla del término a definir (ver ejemplos 1 a 13) indica un comentario del locutor sobre su propia enunciación (AUTHIER-REVUZ, 1984). Como este aspecto excede el presente trabajo, para ampliar el tema se recomienda consultar Tosi (2014). Aclaramos que el subrayado en los ejemplos es nuestro y se usa para señalar un término relevante para el abordaje.

${ }^{8}$ De acuerdo con Ramírez Gelbes (2004), el verbo ser es un verbo semánticamente vacío, "insensible al tiempo y al aspecto semántico". Por ello, se convierte en el verbo adecuado para la constitución de
} 
los ejemplos (1) y (2), el verbo "ser", en su función "identificadora", provee una descripción estable que es válida para todo contexto posible, pues excede los límites de la instancia de la enunciación. Se muestra que "ira" equivale a "un enojo muy grande y violento" y el "guaraní", a la "lengua originaria de los pueblos que habitan en el Paraguay y las zonas limítrofes" y, así, quedan excluidas otras acepciones. En general, al igual que observó Zoppi-Fontana en su análisis, los términos definidos son sustantivos (nombres de cosas u objetos) en desmedro de otras clases de palabras (verbos, conectores, adverbios, etc.), lo cual evidencia la relevancia dada al saber enciclopédico por sobre la reflexión sobre el lenguaje. En estos casos, tal como comenta Zoppi-Fontana (2007), se trata de definiciones de cosas, más que de palabras, pues vehiculizan un discurso sobre el mundo y no sobre la lengua. Además, al utilizarse el verbo de existencia ser, no uno de denominación, la relación parecería establecerse fuera del sistema, entre el signo y el objeto que le sirve de referencia y, por ello, la proposición formulada pasa a ser de tipo referencial, plausible de considerarse verdadera o falsa.

(1) El tigre, enojadísimo al reconocer a aquel loro pelado que él creía haber muerto, y que tenía otra vez lindísimas plumas, juró que esa vez no se le escaparía, y de sus ojos brotaron dos rayos de ira ${ }^{13}$ cuando respondió con su voz ronca:

-iA-cer-ca-te más! ¡Soy sor-do!

${ }^{13}$ La ira es un enojo muy grande y violento.

(p. 46, Cuentos de la Selva, H. Quiroga).

(2) -¡Los dos se han herido! ¡Esos son asuntos de ustedes en el monte! ¡Aquí está bajo nuestra protección! ¡No se pasa!

-Paso -rugió por última vez el tigre.

-Ni nunca -respondieron las rayas.

(Ellas dijeron "ni nunca" porque así dicen los que hablan guaraní ${ }^{8}$, como en Misiones).

${ }^{8}$ El guaraní es la lengua originaria de los pueblos que habitan en el Paraguay y las zonas limítrofes.

(p. 77, Cuentos de la Selva, H. Quiroga).

Un efecto similar se logra a través de la coordinación asindética o yuxtaposición, dada a través de los dos puntos que, según Authier-Revuz (1984), funcionan como una reformulación cercana a las frases que presentan "es decir" u "o sea". De este modo, nos encontramos ante: "zumbar", es decir, "producir un sonido continuado"; inercia", o sea, "rutina o desidia" ( $c f .3)$; "soba", es decir, "paliza o castigo por medio de golpes"; "winchester", o "fusil de repetición diseñado por el estadounidense Oliver F. Winchester" (cf. 4).

predicados oracionales que refieren específicamente a propiedades, como es el caso de las definiciones. Además, la autora establece una diferenciación entre el verbo "ser" y "estar". Mientras que el primero provee una descripción estable, perenne o permanente, o bien absoluta a la manera de una; el verbo estar constituye una descripción inestable, en movimiento o en cambio, como la descripción de algo que ya ha terminado y, por lo tanto, va a transformarse o puede transformarse: una descripción, en fin, válida dentro de los límites de la instancia de la enunciación. 
(3) Otras veces, alineados en el banco, zumbaban ${ }^{2}$ horas enteras imitando el tranvía eléctrico. Los ruidos sacudían asimismo su inercia ${ }^{3}$, y corrían entonces mordiéndose la lengua y mugiendo, alrededor del patio.

\footnotetext{
${ }^{2}$ Zumbar: producir un sonido continuado.

${ }^{3}$ Inercia: rutina, desidia.

(p. 23, La gallina degollada, H. Quiroga)
}

(4) Yo hice correr una bala en la recámara del winchester ${ }^{13}$, para enviarla al puma entre los dos ojos, cuando uno de los cazadores me puso la mano en el hombro diciéndome:

-No le tire, patrón. Ese bicho no vale una bala siquiera. Vamos a darle una soba ${ }^{14,}$ como no la llevó nunca.

\footnotetext{
${ }^{13}$ Winchester: fusil de repetición diseñado por el estadounidense Oliver F. Winchester. El sentido se utiliza, en sentido amplio, para referir a cualquier arma de la empresa Winchester Repeating Arms Company.

${ }^{14}$ Soba: paliza, castigo por medio de golpes.

(p. 50, La gallina degollada, H. Quiroga)
}

Como ya explicamos, cuando en las notas al pie, aparece el significado de un término, se descartan otras acepciones y así se limita y direcciona la interpretación hacia un único sentido posible. Por ejemplo, en (3) vemos que el texto les atribuye un estado de inercia a los niños "idiotas" del matrimonio Mazzini-Ferraz. La nota correspondiente define la inercia como "rutina y desidia", y excluye el significado técnico dado por la Física -"propiedad de los cuerpos de mantener su estado de reposo o movimiento, si no es por la acción de una fuerza", según una de las acepciones del Diccionario de la Real Academia Española (DRAE)-, que podría tener una mayor relevancia en la propia narración, en la medida en que en esta se cosifica a esos personajes, y su inercia podría entenderse como una propiedad física más que a un estado subjetivo de desidia ${ }^{9}$.

Si nos referimos a (4), la polisemia del término "soba" presente en el texto literario ofrece al lector diversos sentidos y abre un abanico de posibilidades acerca de lo que le sucederá al tigre ${ }^{10}$. Sin embargo, esta multiplicidad de opciones se obtura cuando la nota explicita solo una de ellas. El lector entonces no transita en la incertidumbre de lo que le podría suceder al personaje, sino que ya sabe efectivamente que los cazadores quieren "propinarle una paliza".

En suma, tanto el uso del verbo "ser" como de los dos puntos constituyen procedimientos denominativos que, por un lado, intentan ocultar la subjetividad y el

\footnotetext{
${ }^{9}$ Esta es una posible interpretación, dentro de las diversas posibilidades de sentido posibles.

${ }^{10} \mathrm{El} D R A E$ ofrece estos significados para "soba":

1. tr. Tocar repetidamente algo pasando la mano.

2. tr. Manejar y oprimir algo repetidamente a fin de que se ablande o suavice.

3. tr. Estropear algo por usarlo o tocarlo mucho.

4. tr. coloq. Manosear a alguien.

5. tr. coloq. Golpear a alguien, darle una paliza.

6. tr. coloq. p. us. Molestar, fastidiar con trato impertinente.

La nota al pie mencionada presenta la acepción 5.
} 
comentario del locutor-experto y, por el otro, contribuyen a generar el efecto de literalidad: se muestra un sentido, como si este fuera el único que existiera.

\section{b) Las definiciones formuladas mediante expresiones metalingüísticas}

Si bien los verbos de denominación son transitivos y suponen dos participantes: un agente que asigna un nombre y un paciente que lo recibe, el uso de ciertas expresiones impersonales permiten dejar indeterminado al agente de denominación. Según se explicó en un trabajo anterior sobre la formulación de definiciones en los libros texto (TOSI, 2008), ciertas expresiones metalinguiísticas -"recibe el nombre", "se llama", "es conocido como" y "denominamos", entre otros-, actúan como comentarios denominativos (GÜLICH y KOTSCHI, 1995, CIASPUSCIO, 2007 y TOSI, 2008) que buscan desagentivar la definición para lograr un efecto de sentido de mayor objetividad, neutralidad y cientificidad. Sin embargo, tal como quedó demostrado, estos elementos lingüísticos evidencian la subjetividad y la alteridad, en la medida en que no solo contribuyen a modelar un determinado ethos pedagógico (TOSI, 2008), sino que también vehiculizan, en diferentes niveles, puntos de vista ajenos.

En los casos de las notas aquí abordadas, comprobamos que prevalecen las definiciones formuladas mediante expresiones metalingüísticas impersonales, principalmente a través del "se impersonal" ( $c f .5$ y 6) y la perífrasis verbal modal del tipo "quiere decir" ( $c f .7$ y 8).

(5) Y una noche de lluvia estaba el hombre leyendo en su cuarto, muy contento porque acababan de componer el techo de paja, que ahora no se llovía ${ }^{24}$ más; estaba leyendo cuando oyó que llamaban.

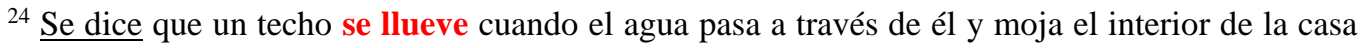
(p. 65, Cuentos de la selva, H. Quiroga).

(6) -Bueno, señor, iba tan rápido aquel engendro ${ }^{117}$, y tan encorvado, que no puedo asegurarle nada. Pero si usted me está preguntando si era el señor Hyde... ¡Sí creo que era él!

${ }^{117}$ Se llama engendro a un ser que no posee la forma o las proporciones adecuadas.

(p.74, El extraño caso del doctor Jekyll y el señor Hyde, R. Stevenson).

(7) Parecía irradiar una bondad y una inocencia de otras épocas, solo que con un toque de altivez, ${ }^{67}$ como el de alguien que tiene buenos motivos para estar conforme consigo mismo.

${ }^{67}$ Altivez quiere decir "orgullo".

(p. 47, El extraño caso del doctor Jekyll y el señor Hyde, R. Stevenson). 
(8) Convinieron ${ }^{10}$ en que cuando Pedrito viera al tigre, lo distraería charlando, para que el hombre pudiera acercarse despacito con la escopeta.

${ }^{10}$ Convenir en algo quiere decir "ponerse de acuerdo" (p. 46, Cuentos de la selva, H. Quiroga).

En cuanto a (5), la nota se relaciona con el nivel de la variedad lingüística, ya que la expresión "un techo se llueve" refiere al sentido que esta adquiere en el habla coloquial de ciertas zonas de la Argentina y Uruguay -en el resto de Latinoamérica y España prácticamente no suele utilizarse-, aunque no quede explicitada tal información. En este caso, la inserción de la forma desagentivada del "se impersonal" (cf. "se dice"), oculta la fuente concreta de la definición, que puede ser atribuida a la voz o uso popular. Por su parte en (6), el uso del impersonal en "se llama" también deja indeterminado el agente de denominación, y la fuente de atribución de la acepción de "engendro" queda así indefinida.

Respecto de las perífrasis modales, estas presentan como necesario o posible lo expresado por el verbo principal (GARCÍA NEGRONI, 2016, p. 355). En el caso de las que se encuentran en las definiciones aquí indagadas, la perífrasis del tipo "quiere decir" expresa el significado del término como ineludible, al estilo de una equivalencia; incluso, la expresión que la define se encuentra modalizada autonómicamente (MELHOR CONFERIR COM O AUTOR, MAS CREIO QUE SEJA ASSIM COMO SUBSTITUÍ) mediante el uso de las comillas: altivez es "orgullo"; convenir es "ponerse de acuerdo". De esta forma, el locutor-experto se desdobla señalando mediante las comillas el término que consideraría equivalente.

Por lo hasta aquí descripto, estas expresiones metalingüísticas tienen un alto agrado de desagentivación. Sin embargo, a diferencia de las anteriores, estas introducen expresiones metalingüísticas que materializan la acción de denominación.

\section{c) Definición más interpretación textual}

En gran cantidad de notas al pie, a la definición del tipo "A es X” se le añade una interpretación vinculada al uso aparente que se le da al término en el texto. Como lo ilustran (9) y (10), las notas presentan la definición seguida por una explicación del significado que supuestamente adquiere tal vocablo en ese contexto.

(9) -Mi pobre amigo Utterson -dijo-, ¡qué desafortunado eres al tenerme como cliente! No he visto jamás a nadie tan afligido como tú por ese testamento mío, salvo a ese pedante irreductible ${ }^{64}$ e Lanyon por lo que él llama mis herejías científicas. Sí ya sé que es un buen colega, no me pongas esa cara... un colega excelente, y siempre tengo ganas de volver a verlo. Pero es un pedante irreductible, bruto y fanfarrón. Nunca nadie me decepcionó más que Lanyon.

${ }^{64}$ Un pedante es aquel que exhibe sus conocimientos ante los demás (los tenga o no). El personaje considera la pedantería del doctor Lanyon como irreductible, o sea, imposible de cambiar. (p.44, El extraño caso del doctor Jekyll y el señor Hyde, R. Stevenson). 
(10) -No señor -fue la respuesta-. No quise ser indiscreto. En general, me resisto bastante a hacer preguntas; es algo que me recuera demasiado al Día del Juicio Final ${ }^{27}$. Se empieza con una pregunta, y es como mover una piedra.

${ }^{27}$ Según la doctrina cristiana, en el Día del Juicio Final, Dios juzgará a los muertos según sus obras. Enfield alude a que no le corresponde a él investigar y juzgar a los demás, ya que este tipo de indagaciones puede terminar afectando a todos

(p.30, El extraño caso del doctor Jekyll y el señor Hyde, R. Stevenson).

Por un lado, en (9) la nota define no solo el sustantivo "pedante" sino la frase nominal, "pedante irreductible". En efecto, primero, se ofrece la definición del sustantivo ("un pedante es ...") y luego la del adjetivo, a través de una reformulación parafrástica: "irreductible, o sea imposible de cambiar". Según García Negroni (2009, p. 48), la reformulación parafrástica "muestra por parte del locutor, que retoma algún elemento anterior para presentarlo de otro modo o para puntualizar su significado, su voluntad de ejercer un cierto control metadiscursivo de la producción del sentido". En nuestro caso, el locutor-experto explica la pedandetería del personaje precisando el significado de "irreductible"; de esta forma no ejerce un control metadiscursivo, en términos de García Negroni (2009), sino también interpretativo. Al igual que en los otros ejemplos, la intervención del locutor-experto no se manifiesta explícitamente -no hay marcas de primera persona-, sino que queda encubierta en la narración en tercera persona ("El personaje considera...”).

Por otro lado, la nota de (10) proporciona información enciclopédica acerca del significado de "Juicio Final". La fuente del discurso ajeno -“doctrina cristiana"- es incorporada mediante la preposición "según", que "permite introducir puntos de vista ajenos con los que el sujeto de la enunciación podrá o no identificarse en la continuidad discursiva" (GARCÍA NEGRONI, 2008). En este caso, el locutor-experto retoma el punto de vista manifiesto, es decir el correspondiente a la doctrina cristiana, y hace de este el objeto de su propia enunciación. Es así que, a la luz del término expuesto "Día del Juicio Final", el locutor-experto intenta explicar la actitud de uno de los personajes, introduciendo así, una interpretación - por consiguiente, subjetiva, relativa-sobre el texto.

Asimismo, se detectan otros ejemplos en los que además de la definición se introduce un adverbio ( $c f .11)$ o frase adverbial ( $c f .12)$ que limita el alcance del vocablo y se circunscribe el sentido al que se supone dado en el texto. El adverbio "aquí", de (11), restringe el sentido de la palabra "desliz" a la acepción que el locutor-experto le asigna en ese caso. Por otra parte, como se observa en (12), "el padrenuestro" se equipara a "una oración que los cristianos rezan de memoria". Pero como la definición no corresponde al contexto específico en que es utilizado y al sentido connotativo que adquiere en el relato, el locutor-experto añade una explicación que introduce mediante la frase adverbial "en este caso". Así, quedaría manifiesto que los venados todas las mañanas repiten una oración como si fuera o la manera de un padrenuestro ${ }^{11}$.

${ }^{11}$ En una de las acepciones de "padrenuestro", el DRAE indica que, en tanto locución verbal coloquial, significa: "Tener algo en la memoria con tanta claridad y orden que puntualmente se pueda referir". 
(11) - Chantaje, supongo; un hombre honrado que se vio forzado a pagar un ojo de la cara por algún desliz ${ }^{26}$ de su juventud.

${ }^{26}$ Aquí la palabra desliz se refiere a una acción vergonzosa.

(p. 30, El extraño caso del doctor Jekyll y el señor Hyde, R. Stevenson).

(12) Había una vez un venado - una gama- que tuvo dos hijos mellizos, cosa rara entre los venados. Un gato montés se comió a uno de ellos, y quedó sólo la hembra. Las otras gamas, que la querían mucho, le hacían siempre cosquillas en los costados. Su madre le hacía repetir todas la mañanas, al rayar el día, la oración de los venados. Y dice así:

I. Hay que oler bien primero las hojas antes de comerlas, porque algunas son venenosas.

II. Hay que mirar bien el río y quedarse quieto antes de bajar a beber, para estar seguro de que no hay yacarés.

III. Cada media hora hay que levantar bien alto la cabeza y oler el viento, para sentir el olor del tigre.

IV. Cuando se come pasto del suelo hay que mirar siempre antes los yuyos, para ver si hay víboras.

Este es el padrenuestro ${ }^{9}$ de los venados chicos. Cuando la gamita lo hubo aprendido bien, su madre la dejó andar sola.

${ }^{9}$ El padrenuestro es una oración que los cristianos rezan de memoria; en este caso, se refiere a la oración que conocen de memoria los venados.

(p. 59, Cuentos de la selva, H. Quiroga).

Pero también encontramos ejemplos en los que el locutor-experto señala en las notas al pie "qué quiso decir el narrador", como si esto fuera posible, como si la lectura fuera transparente y unívoca ( $c f .13)$. Su interpretación se suele introducir con la forma "referir", que expresaría una correspondencia supuestamente "directa" (X refiere $Y$ ) con la realidad (un verbo también presente en 11 y 12), a la que se le suma una información enciclopédica sobre Friedich von Schelling y Samuel Taylor Coleridge (cf. 13).

(13) Al tratar este delicado asunto convendrá, quizá, recordar, las palabras de Oribe sobre los plagios de Coleridge: ¿Era para Coleridge imprescindible copiar a Schelling? ¿Lo hacía in forma pauperis? ${ }^{20}$ de ningún modo. He aquí el enigma.

20 ¿Era para Coleridge imprescindible copiar a Schelling? ¿Lo hacía in forma pauperis?: el narrador se refiere a la influencia que la escritura el romántico alemán Friedich von Schelling (1775-1854) ejerció sobre la obra del poeta Samuel Taylor Coleridge (1772-1834), no por pobreza formal, sino debido al entusiasmo que todo alemán provocaba entonces en Inglaterra.

(p. 20, El perjurio de la nieve de A. Bioy Casares).

En suma, en todos estos casos, las notas dirigen la comprensión al explicitar cuál es, según el locutor-experto, el sentido que adquiere el vocablo o la expresión en ese determinado contexto. Si bien la interpretación dada queda solapada tras las marcas de 
desagentivación (prevalece la narración en tercera persona), ciertos recursos como la definición seguida de explicación y los modos de referir la palabra ajena, así como los adverbios, las frases adverbiales y las reformulaciones parafrásticas que anclan el sentido dado por el locutor-experto, se evidencian como huellas de subjetividad. De esta manera, al imponer una cierta interpretación en el lector, estos recursos funcionan como señales del control discursivo que busca ejecutar el locutor-experto.

\section{Conclusiones}

El objeto de estudio de este trabajo ha sido el espacio periférico de las colecciones literarias. Si bien el paratexto editorial suele ser soslayado por su carácter marginal y subsidiario, el análisis aquí realizado demostró su relevancia, pues no solo vehiculiza representaciones sobre la literatura y los destinatarios, sino que exhorta sobre una forma de leer y de acceder a la literatura en la escuela.

A lo largo del artículo analizamos las notas al pie de un corpus de colecciones escolares de literatura editadas en la Argentina, que son utilizadas con gran asiduidad en las instituciones escolares. Si bien otras investigaciones ya habían presentado estudios discursivo-enunciativos sobre las notas al pie de página en colecciones literarias (ORLANDI, 1990 y ZOPPI-FONATANA, 2007), en esta ocasión nos ocupamos de las notas de colecciones escolares en español, que son producidas en el marco de las propuestas editoriales (es decir, no son notas realizadas por el autor) y nos encargamos de indagar los mecanismos lingüísticos desplegados que establecen un determinado sentido de lectura y fijan la interpretación en una dirección.

Según explicamos, las notas que acompañan la obra literaria suelen estar a cargo de un especialista en literatura y, en general, ofrecen definiciones sobre ciertos términos que este locutor-experto supone desconocidos por el destinatario-alumno y que considera fundamental para comprender el texto. De ahí que pueda afirmarse que, en estos espacios paratextuales, se configura un locutor-experto atento a dos fines: por un lado, a guiar la lectura del destinatario-alumno y, por el otro, a auxiliar al destinatario-docente en el abordaje de la obra. De esta forma, prevalece el imaginario de que los destinatarios -tanto alumnos como docentes- no podrían producir sentidos por sí mismos, o bien podrían elaborar interpretaciones "erradas" o "incompletas", y por ello necesitan acceder a información enciclopédica complementaria para abordar los textos sin fallas. Así, en las notas, el locutor-experto introduce una de todas las posibles acepciones de los términos, lo cual restringe la multiplicidad de sentidos y alienta una lectura unidireccional. De ahí se desprende que el ideal de lectura propuesto por dichas colecciones es el "contenidista", pues el foco de la lectura está puesto en reconocer el significado "correcto" de los vocablos, atendiendo a la información enciclopédica (no metalingüística) que conduce a una lectura "adecuada", y se encuentra alejado de las perspectivas centradas en la reflexión lingüística o estilística, o en el mero disfrute de las obras.

Asimismo, el análisis ha revelado que el locutor-experto introduce interpretaciones respecto del texto en forma solapada, evitando mostrar que son productos 
de un punto de vista. Esto no hace más que reafirmar que en las colecciones analizadas prevalece la concepción de que existe un sentido prefigurado (que se ubica en las notas al pie) y que el lector debe seguir para asir el significado del texto o descubrir la intención del autor, como si esto fuera posible. Las notas podrían generar, además, un efecto "tranquilizador" para el destinatario-docente, puesto que neutralizan la complejidad que implica abordar textos literarios de este estilo (clásicos y canónicos) y, como sostiene Zoppi-Fontana (2007), permiten ejercer un control sobre los sentidos.

También el análisis ha revelado que diferentes recursos lingüísticos contribuyen a producir tal efecto de literalidad que, como ya explicamos, encuentra una ligazón con el tipo de lectura literaria que, tradicionalmente se ha llevado a cabo en la escuela, y que consiste en que los alumnos asuman una interpretación autorizada (ya sea del docente, ya sea de un especialista) y se mantengan alejados de una lectura independiente y personal. En efecto, el locutor-experto configurado en las notas, en su pretensión por transmitir la interpretación del texto como si fuera objetiva e imparcial, tiende a borrar las marcas de subjetividad mediante diversos recursos de despersonalización; no obstante, estos emergen como señales de control discursivo.

Luego de haber rastreado e indagado las características y funciones de las definiciones en las notas al pie de nuestro corpus, las agrupamos en tres tipos en orden decreciente de despersonalización y de solapamiento de la interpretación del texto, a saber: 1) las definiciones por equivalencia, expresadas mediante el verbo ser y la yuxtaposición, 2) las definiciones formuladas con expresiones metalingüísticas impersonales, principalmente a través del "se impersonal" y la perífrasis verbal modal del tipo "quiere decir", y 3) las definiciones más interpretación textual, en la cual ciertos recursos, como los modos de referir la palabra ajena, reformulaciones parafrásticas o frases adverbiales, que pretenden "anclar" los sentidos, funcionan como marcas de subjetividad y alteridad.

Por todo lo expuesto, podemos concluir que las notas se configuran como zonas didácticas que imponen gestos de interpretación que, al ocultar la subjetividad y el punto de vista, contribuyen a crear el efecto de "literalidad". Creemos que, para la labor docente, resulta de gran utilidad desnaturalizar la idea de la existencia de la "literalidad" en los textos, pues el concepto de sentido literal revela la persistencia de una acepción puramente informacional, neutra y objetiva del sentido.

Solo resta agregar que el análisis aquí realizado ha tenido la pretensión de fomentar la reflexión respecto de ciertas representaciones sociales arraigadas respecto del alumno, el profesor, la lectura y la literatura, que orientan y condicionan los procesos de diseño, edición, lectura y disfrute (o no) de la literatura. Pensar sobre estos imaginarios y desnaturalizarlos podría propiciar un sincero encuentro entre los lectores y los textos, y contribuir a forjar experiencias de lectura más autónomas, gratificantes y abiertas a la multiplicidad de sentidos. 


\section{Corpus citado (ejemplos)}

BIOY CASARES, Adolfo. El perjurio de la nieve. Buenos Aires: LyC, Colihue, 1983. Décima reimpresión. 2008. Notas al pie a cargo de Prof. Hebe Monges.

QUIROGA, Horacio. Cuentos de la selva. Buenos Aires: Colección de los anotadores, La estación (Mandioca), 2009. Notas al pie a cargo de Alejandra Laera.

QUIROGA, Horacio, TRILLO, Carlos y BRECCIA, Alberto. La gallina degollada y otros textos con sangre. Buenos Aires: Cántaro (Grupo MacMillan), 2013. Notas al pie a cargo de Natalia Frate.

STEVENSON, Robert. El extraño caso del doctor Jekyll y el señor Hyde. Colección de los anotadores, editado por La estación (Mandioca), 2010. Notas al pie a cargo de María Inés Indart.

\section{Bibliografía}

ALVARADO, Maite. Paratexto. Buenos Aires: EUDEBA, 1992.

ANSCOMBRE, J.C.; DUCROT, O. L'argumentation dans la langue. Bruselas: Pierre Madariaga Éditeur, 1983.

AUTHIER-REVUZ, J. Hétérogénéité(s) énonciative(s). Langages, 73, 98-111, 1984.

BOMBINI, G. Los arrabales de la literatura. La historia de la enseñaza literaria en la escuela secundaria argentina (1860-1960). Buenos Aires: Miño y Dávila, 2004.

Avatares en la configuración de un campo: la didáctica de la lengua y la literatura. Lulú Coquette [Revista de didáctica de lengua y literatura], n.1, 24-33, 2001.

CIAPUSCIO, G. Comentarios y evaluaciones del léxico en el discurso científico: aspectos estructurales y funcionales. Los estudios del discurso: nuevos aportes desde la investigación en Argentina. Bahía Blanca: Editorial de la Universidad del Sur, 2007.

COLOMER, T. La didáctica de la literatura: temas y líneas de investigación e innovación. Biblioteca virtual universal. Madrid: Editorial del Cardo, 2010.

DE SOUZA MINAYO, M.C. La artesanía de la investigación cualitativa. Buenos Aires: Lugar, 2009.

DUCROT, O. El decir y lo dicho. Barcelona: Paidós, 1984, 2001.

FOUCAULT, M. El orden del discurso. Buenos Aires: Tusquets, 2008 [1970]. 
GARCÍA NEGRONI, M.M. Para escribir bien en español. Claves para una corrección de estilo. Buenos Aires: Waldhuter, 2016.

Reformulación parafrástica y no parafrástica y ethos discursivo en la escritura académica en español. Contrastes entre escritura experta y escritura universitaria avanzada. Letras de Hoje, v. 44, n. 1, 46-56, 2009.

Subjetividad y discurso científico-académico. Acerca de algunas manifestaciones de la subjetividad en el artículo de investigación en español. Signos, v. 41, 66, 5-31, 2008.

GÜLICH, E.; KOTSCHI, T. Discourse production in oral communication. En: QUASTHOFF, U. (Ed.) Aspects of oral communication. Berlín: Mouton de Gruyter, 1995.

ORLANDI, E.P. A Linguagem e seu funcionamento. As formas do discurso. Campinas: Pontes, 2009.

Terra a vista: discurso do confronto, velho e novo mundo. Campinas: Ed. da Unicamp, 1990.

PÊCHEUX, M. Semântica e Discurso. Uma crítica a afirmacao do obvio. Trad. Bras. Campinas: Editora de Unicamp, 1998 [1975].

PIACENZA, P. GOLU el Canon escolar entre la biblioteca y el mercado. Catalejos [Revista sobre lectura, formación de lectores y literatura para niños], v. 1, n. 1, 09-131, 2015.

Enseñanzas de la literatura y procesos de canonización en la escuela media argentina (1966-1976). Lulú Coquette, n. 1, 86-96, 2001.

RAE. Diccionario de la Real Academia Española. Madrid: RAE, 2017. Disponible en http://www.rae.es/.

RAMÍREZ GELBES, S. El aspecto verbal y el significado léxico: acerca de ser y estar. Signos Universitarios Virtual, Universidad del Salvador: Buenos Aires, 2004.

TOSI, Carolina. De las colecciones escolares a los audiolibros. Un análisis sobre la mediación editorial y las materialidades en la literatura destinada a jóvenes. Cultura Editorial, v. 1, n. 1, 2016.

La emergencia de las colecciones de literatura infantil y juvenil, y su impacto en la industria editorial. Los casos Robin Hood y Biblioteca Billiken. Catalejos, v. 1, n. 1, 132-158, 2015.

Children's Literature teaching an otherness. An Analysis on publishing mediation. En: ULLOA, T.F.U. (Ed.). Otherness in Hispanic Culture. Bakersfield: Cambridge Scholars, 2014. cap. 25, pp. 485-500. 
TOSI, C. La definición en los libros de texto. Acerca de los comentarios metadiscursivos de denominación en la conformación del ethos disciplinar. Cuadernos del Sur - Letras, 38, 29-48, 2008.

ZOPPI-FONTANA, M.G. En los márgenes del texto: intervalos del sentido en movimiento. Páginas de Guarda, n. 4, 11-39, 2007.

Artigo recebido em: janeiro de 2017.

Aprovado e revisado em: março de 2017.

Publicado em: abril de 2017.

\section{Para citar este texto:}

TOSI, Carolina. La configuración del efecto de literalidad en las colecciones escolares de literatura. El caso argentino. Entremeios [Revista de Estudos do Discurso, on-line], Seção Temática - Língua(gem) e Ensino, Programa de Pós-Graduação em Ciências da Linguagem (PPGCL), Universidade do Vale do Sapucaí (UNIVÁS), Pouso Alegre (MG), vol. 14, p. 293-310, jan. - jun. 2017.

DOI: http://dx.doi.org/10.20337/ISSN2179-3514revistaENTREMEIOSvol14pagina293a310 